\title{
About Some Service Guns of the Hungarian Police - From a Different Point View
}

\section{Kund REGÉNYI ${ }^{\oplus}$}

\begin{abstract}
In 2020, the Hungarian Police started replacing its obsolete service handguns. Taking the opportunity, the article gives an overview of the major former service handguns of the Hungarian Police, presenting their advantages and disadvantages, searching for the reasons of their partial failure. The approach is less technical; in addition to outlining the political and economic background, the end-user experience is also presented. As a conclusion, the article welcomes the model replacement, mentioning some critical points as well.
\end{abstract}

Keywords: service handgun, PA63, P9RC, HK USP, structural mass, calibre, holster

\section{Introduction}

There have been generally more technical articles and studies published on regularised service guns used by certain police forces. Undoubtedly, technical parameters are extremely important when describing and characterising a service handgun, but the approach based on a narrow criteria does not provide satisfactory answers to several questions. ${ }^{2}$ This study attempts to introduce some selected handguns used by the Hungarian police from an economic, political and historical point of view, deemphasising the technical approach, which is complemented by some viewpoints of the practical users, i.e. the police operators carrying and firing a firearm. I hope that in doing so, the article will be of benefit to those who are not exclusively interested in the technical approach.

Kund Regényi, PhD, University of Public Service, Assistant Lecturer, police shooting instructor, sports shooter. E-mail: Regenyi.Kund@uni-nke.hu

2 Two well-known examples in English: Ian Hogg, Pistols of the World (Krause, 2004); A E Hartink, The Complete Encyclopedia of Pistols and Revolvers (Chartwell, 2013). 


\section{PA-63 - One can have too much of a good thing}

The subtitle could have been different, such as the "great survivor" or "how to spoil something good out of mere good intent". What is it about then? PA-63 first appeared in the mid-1960s in the composition of the then Hungarian People's Army and the special party militia, the Workers' Guard. The pistol was a product of the then existing Weapons and Gas Appliances Factory (Fegyver- és Gázkészülékgyár - FÉG). Its construction is essentially a very modest modification of one of the most famous police pistols, the Walther PP. The most significant change can be seen in the material of the weapon's frame, which is made of aluminium alloy. The calibre of the pistol, which is now known as the $9 \times 18$ Makarov, became a newly regularised service pistol calibre of the formerly existing federal system called the Warsaw Pact, in accordance with political and military principles and expectations. Other minor changes can be detected in the design of the impact pin safety device.

By the mid-1960s, FÉG reached decades of experience in the production of various Walter PP clones. This led to that positive decision that instead of the common practice of the Warsaw Pact, which was the takeover of the production licence for the Soviet Makarov pistol, and the following production and adaption of it, an independent Hungarian solution could be created. It can be said that the PA-63 was born under a lucky star and it had all the opportunity for a long, successful and esteemed career. As far as the length of his career is concerned, the type has fulfilled and even exceeded expectations, since the PA-63 is the regularised service weapon of the Hungarian police in many units up to this day.

However, the pistol is by no means widely recognised among users. As for the reasons, we must mention in the first place the moral obsolescence of the weapon and its actual abrasion that can be experienced in practice. Today, the considerable number of spare parts accumulated for that type has been already sold out and used up. Although until the first decade of the second millennium the type could be overhauled and maintained at "industrial" level, however, due to the lack of components and the aging of the aluminium alloy, a significant proportion of PA-63s operate unreliably and therefore, the type became unsuitable for service use (where reliable operation is a key requirement).

Even if a better-maintained, less-worn piece can still be found, there are two more very unpleasant circumstances that stand in the way of the weapon's popularity. It is very difficult to make it ready, which is a significant challenge, especially for lowstatured operators with smaller hand. Besides, if one manages to make the gun ready and fire a shot or shots, the significant repulsive force will cause serious difficulties. It can be said that firing a few dozen shots during a training with PA-63 requires serious determination and self-discipline.

István Nagy and Zoltán Kovács, Kézi lőfegyverek [Handguns] (Budapest: Zrínyi, 1986), 158-159. 
The causes of these problems are no longer so obvious, but they are still relatively easy to identify. The most important and fundamental reason is the calibre chosen for the weapon. The $9 \times 18$ Makarov is an ammunition with a relatively significant muzzle energy compared to the sheath length, and the initial velocity of the projectile is also relatively high. These parameters are close to the $9 \times 19$ Parabellum, and to the $9 \times 17$ Browning short, which is also known as 380 ACP. This is understandable while the Makarov pistol and ammunition in the Soviet Union were systematised to replace the $7.62 \times 25$ Tokarev with much higher muzzle energy ammunition (and of course, pistols and submachine guns sized for this ammunition). ${ }^{4}$ However, if we take a look at the different PP pistols, it is striking that they are most often manufactured with the 7.65 Browning, i.e..32 ACP, and the already mentioned $9 \times 17$ Browning short calibre. In other words, the $9 \times 18$ Makarov is located at the top of the operating range of the structure, which is a simple blowback system. In simple terms, the $9 \times$ 18 Makarov is too strong for this small pistol and this locking solution. The selection of the $9 \times 18$ Makarov required the application of a very strong return spring to the weapon. This circumstance explains why it is so difficult to make it ready.

Another cause of the problems lies in the choice for the structural material of the frame. In the 1960s, aluminium seemed to be a popular alternative for the production of service weapons, as it made it easier to be available for users who - and this is still a very important aspect - did not fire primarily the weapon, but carried it. (This advantage, of course, is further enhanced by the emergence and explosive proliferation of polymer frame weapons, which began in the mid-1980s and continues to this day.) However, if you do have to shoot, the PA-63's relatively high muzzle energy coupled with a relatively low structural mass results in a surprisingly large repulsive force of the weapon relative to its size and calibre, and the structural design of the weapon does not help to absorb this repulsive force either. In simple terms, when a shot is fired, the gun kicks like a horse.

Again, it is only worth comparing PA-63 to other Walther PP clones. It can be stated that their structural material is steel, which results in a significant structural mass, so they can be fired very well, not forgetting the calibre with lower mouth energy. It is no coincidence that Walter re-launched its PPK models nearly 100 years after the first design. ${ }^{5}$

In summary, the compulsion to choose a military calibre and a reasonable and up-to-date choice of structural material together, resulted in such neglected disadvantages that prevented the PA-63 from gaining similar popularity and recognition to its mother type among the Hungarian police force.

4 Hornady Critical Defense,.32 Auto: weight $60 \mathrm{~g}$, muzzle velocity $1000 \mathrm{ft} / \mathrm{sec}$, muzzle energy $133 \mathrm{ft} / \mathrm{lb}$; $380 \mathrm{ACP}$ : weight $90 \mathrm{~g}$, muzzle velocity $1000 \mathrm{ft} / \mathrm{sec}$, muzzle energy $200 \mathrm{ft} / \mathrm{lb} ; 9 \times 18$ Makarov: weight $95 \mathrm{~g}$, muzzle velocity $1000 \mathrm{ft} / \mathrm{sec}$, muzzle energy $211 \mathrm{ft} / \mathrm{lb} ; 9 \mathrm{~mm}$ Luger: weight $115 \mathrm{~g}$, muzzle velocity $1135 \mathrm{ft} / \mathrm{sec}$, muzzle energy $332 \mathrm{ft} / \mathrm{lb}$ (www.hornady.com/ammunition/handgun/\#!/) and Privi Partizan $7.62 \times 25$ Tokarev: weight $85 \mathrm{~g}$, muzzle velocity $525 \mathrm{~m} / \mathrm{sec}$, muzzle energy $755 \mathrm{~J}$ (www.prvipartizan.com/search_h.php); 1 grain = 0.0648 gram; $1 \mathrm{ft} / \mathrm{lb}=$ 1.356 Joule; $1 \mathrm{ft} / \mathrm{sec}=0.305 \mathrm{~m} / \mathrm{sec}$.

5 See https://carl-walther.com/defense/products/p/2851962 


\section{The P9RC - Or the easier way may not take you to your destination}

The next pistol we are analysing is called $\mathrm{P}_{\mathrm{RRC}}{ }^{6}$ by the Hungarian police and $96 \mathrm{M}$ by the Hungarian Armed Forces. At first glance, the weapon appears to be a very significant development over the aforementioned PA-63. It can be grasped in its structural material (steel), in its chosen calibre $(9 \times 19$ Parabellum), in its locking solution (tilting barrel rigid locking with grooves and ribs, i.e. Browning II). Significant progress has also been made in the weapon's magazine capacity, 14 rounds, which is made possible by the two-line magazine design. The size of the weapon is also more suitable for open-carry service use, as it falls into the category of the so-called fullsize service weapons. The weapon was originally intended for the civilian market and for export by the FÉG in the mid-1980s, while in the mid-1990s it began to enter the Hungarian Army and then the Hungarian police in increasing numbers.

If these advantages are true (and this is indisputable), then what is the problem? The first one is that the basic construction of the weapon is far from being as successful as the Walther PP. It is essentially a clone of the Smith \& Wesson M59 series. The basic design did not have outstanding success, it was not systematised by major military or police forces, and some of its sub-variants also had only moderate success in the civilian market.

In retrospect, it is very unfortunate that the constructors and decision-makers insisted on the proven (?) mediocrity. Apparently, the factory's machine park was designed for metalworking, the experts of the age thought in and got used to metal weapons, yet, the bold question cannot be avoided: what would have happened if the then revolutionary Glock's licence had been bought? Remember, there was even a significant plastic processing capacity in the country at the time, on the basis of which the production of the then pioneering polymer stock service gun could certainly have been realised. And the very theoretical question is whether FÉG would have been able to benefit from Glock's global success financially, technically and morally. In retrospect, the initial circumstances would have made it possible to embark on the outlined path.

After all this is not the only technical tool that does not reach world standards, but still does a good service to the Hungarian police. This could have happened that way either, but the economic transformation accompanied with the change of the regime, the redevelopment of Hungarian small arms production, which is hardly explainable to an outside observer, has led to the deterioration of weapon production's quality over the years. Paradoxically, a police officer who chooses an older P9RC from one of the first series is much better off, even if the early pistol sight was the same small size used in military weapons at that time, which makes fast and accurate aiming particularly different in poor visibility conditions. However, the much more durable and attractive surface finish of the weapon compensates for it. Early weapons were

Nagy and Kovács, Kézi lőfegyverek, 163. 
also generally of higher quality, with smaller dimensional tolerances during their manufacture, which resulted in greater reliability and accuracy. The low production quality of the later series is especially obvious regarding the lifetime of the weapon. There are such kind of weapons in which there are no longer any dralls on the first two $\mathrm{cm}$ of the inner surface of the barrel, since it has been quite simply worn out. It doesn't need any special imagination or expertise to declare that an accurate hit with such weapons is essentially a matter of luck.

We have already dealt with the redevelopment of Hungarian arms production. This, of course, led to the fact that no parts were available for the P9RC, even if these would not have been expensive anyway, since each spring was manufactured in large batches for a few pence per piece. However, because of the absence of the necessary particles, the maintenance of the weapon can mainly be accomplished through cannibalization, i.e. through the disassembly and reassembly of the certain parts of individual pieces. All these circumstances resulted in that special situation that the predecessor, i.e. the PA-63, has survived the successor i.e. P9RC within some Hungarian police units. This is, of course, due to the fact that earlier, during the Cold War, the necessary components were manufactured and stored up to a much larger stock then today, and were available still decades later, allowing PA-63 to be used for a longer period.

The following question of the holsters applies to both the PA-63 and the P9RC. Both the PA-63 and the P9RC come with a holster that reflects the standards and approach of World War II and is referred to as "elephant-eared" holster by users, which according to the contemporary aspects, does not allow rapid drawing at all. Thus, it could only be achieved with auxiliary (coercive) solutions, which were otherwise incompatible with modern shooting technique. Of course, anyone who wanted to could purchase a modern plastic case for either Walter PP or Smith and Wesson M59 for own money (!), and many did so. And the clever commander looked away...

\section{Heckler und Koch USP / P8 - Or one swallow does not make a summer}

By the beginning of the 2000s, two things became obvious: one is that unfortunately, the replacement of the Hungarian police's service guns cannot be solved from domestic production. The other closely related one is that at least the special police units, which at that time meant the police counter-terrorism service and the county SWATs, ${ }^{7}$ should be allowed to acquire modern, foreign-made guns. The first example

SWAT: Abbreviation from Special Weapons and Tactics, often refers to a specially tasked police unit, which is using these. 
of this was the Jericho F 941 pistol purchased in the early 1990s, which is an excellent construction, but was only available in small numbers.

Due to the change in political circumstances, a professionally excellent decision was made in the early 2000s. According to this, the pistol, called USP ${ }^{8}$ was acquired, which laid the foundations for the Heckler und Koch renaissance in the field of small arms. The decision was, of course, supported by the fact that the gun was also regularised by the German Bundeswehr under type designation P8.

The weapon was another significant step forward, as its size, design and orientation met with all expectations of modern service guns. Besides, this was the first type of weapon in the Hungarian police force to which a gun flashlight can be attached. The operators of the police units have been using this possibility since then.

Another important development is that the weapon has been regularised in two sizes. In addition to the full-size version, the so-called compact design was also standardised, of course, for the elite units serving in civilian clothes. As an example, the close protection operators of the former Republican Guard Regiment can be mentioned in the first place.

Further advantage is that the USP has revolutionised the holsters. This is the first type for which moulded plastic holsters were regularised. ${ }^{9}$ According to the primary usage profile (police special units), these were mounted on a thigh panel, which established the "fashion" of thigh holsters that continues up todays.

The description and appreciation of this type is concluded by presenting a small technical solution. This is the design of the magazine lock/release button, which is not released in the usual way perpendicular to the longitudinal axis of the weapon, but can be operated by pressing it from top to bottom parallel to the height line of the weapon. On the one hand, this solution enables quick release and fast magazine change, on the other hand, it makes the type suitable for small-handed operators as well. In fact, it is a pity that market pressure is still condemning this kind of fixing solution to a walking-on part. This is well illustrated by the fact that both Heckler und Koch and Walther offer several models with two types of release solutions.

So is it everything all right with the Heckler und Koch USP? Technically for sure. Unfortunately, the high price of the weapon, and the presumably low intention for type change, shattered the hope that the Heckler und Koch USP would be a general type change weapon for police forces. Instead, it has become a kind of status symbol, contributing to the expansion of the type cavalcade, and to everything which came attached to it: cumbersome and multiplied purchases of the parts, repetitive obligate trainings, and most importantly, a lack of confidence in our own weapons.

See www.heckler-koch.com/en/products/military/pistols/usp/usp/overview.html

See https://safariland.com/products/model-6004-sls-tactical-holster-19858 


\section{Outlook}

After the long decades of seeking the right path shown above, at the end of the second decade of the 2000s, it seems that the Hungarian police will have the opportunity to change the type of its general handgun. It can be stated that the baselines of the decision give cause for hope. The product of a long-established and worldrenowned arms factory (Ceská Zbrojovka) was selected in two sizes (P-09 and P07). ${ }^{10} \mathrm{~A}$ decision was made to systematise holsters and magazine pouches that seem suitable to support the implementation of modern training and tactical principles. The development of the domestic production capacity gives hope for a long-term, reassuring solution to the issues of maintenance and parts supply.

Of course, there can always be certain excuses found. In fact, we do not yet have references on the durability and dimensional tolerance of the manufactured weapons and components. It is also a fact that the progeny type of the mentioned weapons better corresponds to the current market and professional trends. (Here, of course, we are thinking of the relationship between striker-fired and cock-fired devices.) It is also a fact, however, that a decades-old problem will hopefully be solved within reasonable time by systematising the new P-09 pistols.

\section{REFERENCES}

Hartink, A E, The Complete Encyclopedia of Pistols and Revolvers. Chartwell, 2013.

Hogg, Ian, Pistols of the World. Krause, 2004.

Nagy, István and Zoltán Kovács, Kézi löfegyverek [Handguns]. Budapest, Zrínyi, 1986.

\section{Internet sources}

www.hornady.com/ammunition/handgun/\#!/

www.prvipartizan.com/search_h.php

https://carl-walther.com/defense/products/p/2851962

www.heckler-koch.com/en/products/military/pistols/usp/usp/overview.html

https://safariland.com/products/model-6004-sls-tactical-holster-19858

www.czub.cz/en/defend-and-serve/pistole-defend

10 See www.czub.cz/en/defend-and-serve/pistole-defend 